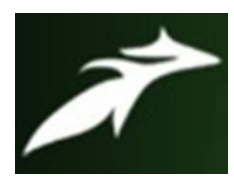

Lekshmi G.S et al, International Journal of Advances in Agricultural Science and Technology,

Vol.8 Issue.1, January-2021, pg. 119-124

ISSN: 2348-1358

Impact Factor: 6.057

NAAS Rating: 3.77

\title{
Measurement of Agricultural Efficiency in Palakkad District, Kerala
}

\author{
Lekshmi G.S ${ }^{1}$; Charutha Reghunathan ${ }^{2}$ \\ ${ }^{1}$ Environmental Resources Research Centre, Thiruvananthapuram, Kerala, India, girijalekshmi26@gmail.com \\ ${ }^{2}$ Government College, Kariyavattom, Thiruvananthapuram, Kerala, India, charuthaa@gmail.com
} DOI: 10.47856/ijaast.2021.v08i1.015

\begin{abstract}
Kerala is one of the highly densely populated states in India. Agriculture is the major source of livelihood of the Keralites. Agricultural sector contributes more than $75 \%$ of state's domestic income. Agriculture and its allied activities hold an important position in state's economy as it is one of the major source of foreign exchange of the state. Agricultural efficiency is the quality of taking the maximum out of the existing resources. It can be simply expressed by showing it as the quotient obtained by dividing output of a production unit by anyone of the factors of production. The area and production of crops in Kerala has resulted certain changes in the agricultural economy of the state over a period of time. The present study is an attempt to determine the agricultural efficiency of Palakkad district. To analyze agricultural efficiency, blocks have been taken as areal unit. Kendall's (1939) formula has been used to determine the agricultural efficiency of Palakkad district. Maps have been prepared by using Arc Gis software 10.3 version.
\end{abstract}

Keywords: Kerala, Agriculture, Agricultural efficiency, Economy, Palakkad district.

\section{Introduction}

Agriculture is the backbone of Indian economy. It is a major source of food and various job opportunities by providing raw materials for the industries (Pandey \& Dwivedi, 2017). Sufficient agricultural production can fulfill the increasing demand of food, so problem of poverty can be solved (Mukherjee \& Khan, 2016). The measurement of agricultural efficiency is to understand whether maximum return per unit area of land has been obtained in a particular physical and cultural milieu with the application of human efforts at the existing level of development. It is the scientific device to study the inherent fertility, productivity and capability of the land (Dutta, 2012). With the assessment of agricultural efficiency it is possible to differentiate more productive and less productive areas and accordingly agricultural plans may be formulated to remove and minimize the regional inequalities in agricultural regions.

\section{Study Area}

Palakkad, the largest district in the state is situated between $10^{0} 20^{\prime}$ to $11^{0} 14^{\prime} \mathrm{N}$ latitude and $76^{\circ} 02^{\prime}$ to $76^{\circ} 54^{\prime} \mathrm{E}$ longitude. The total geographical area of the district is $4480 \mathrm{sq}$. $\mathrm{km}$. The district is bounded by Malappuram and Nilgiri districts on the North, Coimbatore district on the east, Trichur district on the south and Malappuram and Trichur districts on the west (Figure 1). The district has 13 blocks. About $45 \%$ of the total geographical area of the study area is cultivated and nearly $86 \%$ of the net sown area is irrigated (Premakumar et.al,2015). Palakkad district has a tropical climate with an oppressive hot season and fairly assured seasonal rainfall. Bharathapuzha, Bhavani and Parambikulam rivers are the major rivers 


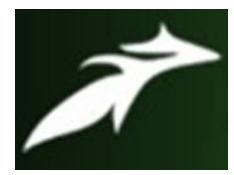

Lekshmi G.S et al, International Journal of Advances in Agricultural Science and Technology,

Vol.8 Issue.1, January-2021, pg. 119-124

ISSN: 2348-1358

Impact Factor: 6.057

NAAS Rating: 3.77

flowing in this district. A unique feature of the highland is Palakkad Gap which has its great impact on agro climatic conditions of the district. Palakkad district stands first in the rice production of state which accounts for about $42 \%$ of the total production of state, hence the district is known as the "Granary of Kerala". Apart from rice, the district also stands first in the production of fruits, vegetables, tamarind, fibre crops etc.

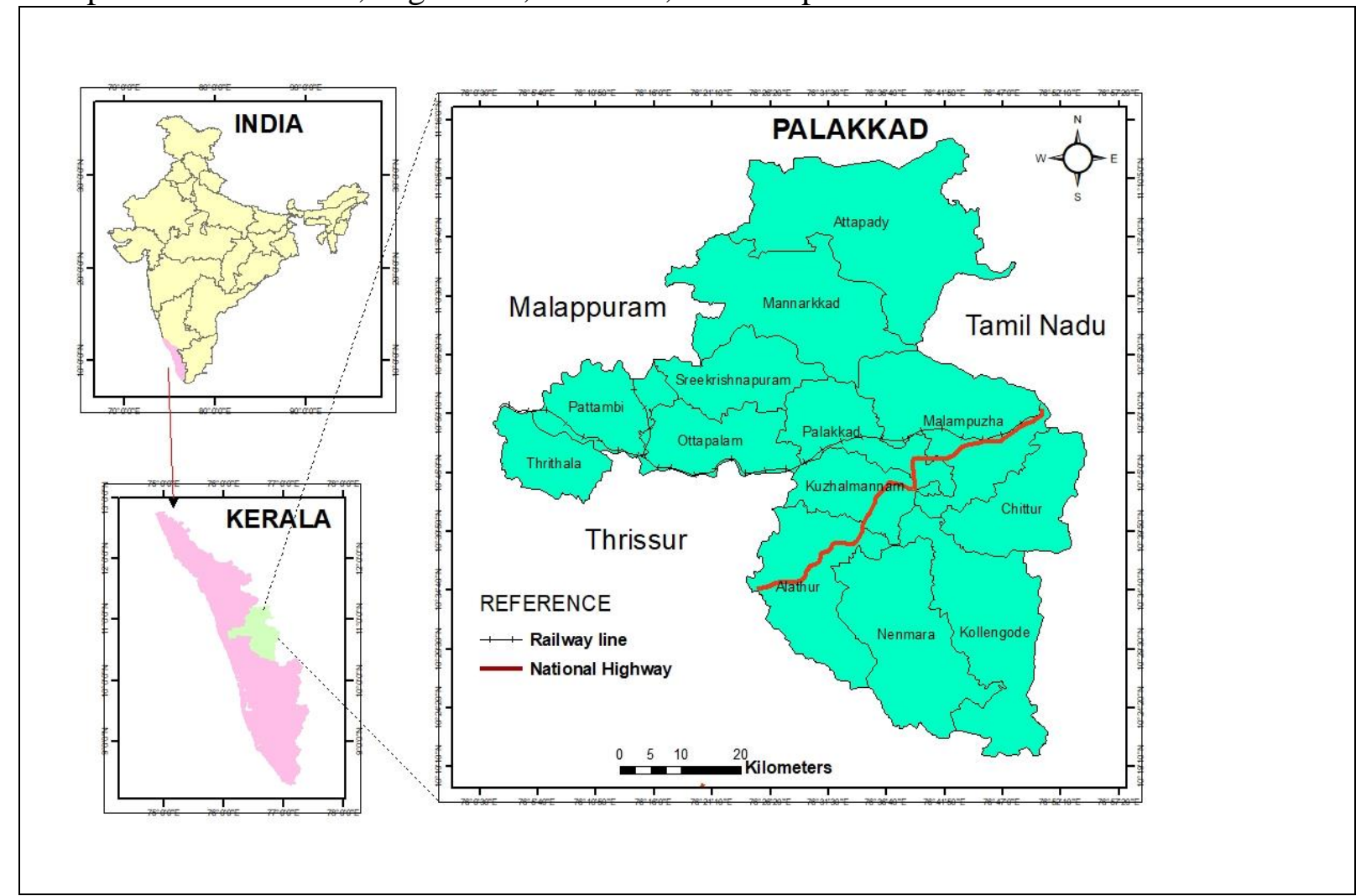

Figure 1: Study Area

\section{Aim and Objectives}

Aim

To calculate the agricultural efficiency of the Palakkad district.

Objectives

- To assess the agricultural productivity of the Palakkad district.

- To delineate the blocks having maximum and minimum agricultural efficiency.

- To provide suggestions to increase agricultural production in the deficient development block of the study area.

\section{Methodology}

The present study was based on secondary data which was collected from Department of Economics and Statistics, Palakkad for the years 2015-2019. Here the average area and production of five years was taken to calculate the agricultural efficiency of the Palakkad 


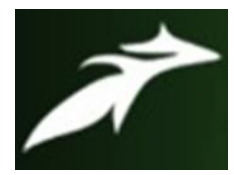

Lekshmi G.S et al, International Journal of Advances in Agricultural Science and Technology,

Vol.8 Issue.1, January-2021, pg. 119-124

ISSN: 2348-1358

Impact Factor: 6.057

NAAS Rating: 3.77

district. Block has been taken as the unit of study. Arc Gis 10.3 version was used for the preparation of maps. M.G. Kendall's method (1939) was used to find out the agricultural efficiency of the district. Ranks are given according to yields per unit of area for each crop in Palakkad district. Then average rank worked out is called as ranking coefficient. The formula is given below.

Ranking coefficient index $=\mathrm{R} 1+\mathrm{R} 2+\ldots . \mathrm{R} 5 / \mathrm{N}$

R- Ranking of yield of individual crop, $\mathrm{N}$ - Number of crop

\section{Results}

\subsection{Agricultural Productivity}

Agricultural productivity of five major crops such as rice, coconut, fruits, vegetables and spices are given in the table 1 and figure 2. Kuzhalmannam block stands first in the productivity of rice. Coconut productivity is expressed in nuts/ha. Attappady block stands first in the productivity of coconut and fruits. Nenmara block which is known as the "Vegetable hub of Kerala" stands first in the productivity of vegetables. In the case of spices productivity, Kollengode block stands first.

Table 1: Productivity of crops $(\mathrm{Kg} / \mathrm{Ha})$

\begin{tabular}{|l|l|l|l|l|l|l|}
\hline Sl.No. & Blocks & Rice & Coconut & Fruits & Vegetables & Spices \\
\hline 1. & Alathur & 258.34 & 72.37 & 282.35 & 118.82 & 226.89 \\
\hline 2. & Attappady & 252.33 & 86.98 & 946.87 & 105.15 & 95.94 \\
\hline 3. & Chittur & 267.91 & 73.77 & 680.67 & 170.03 & 637.77 \\
\hline 4. & Kollengode & 272.79 & 74.47 & 629.38 & 134.27 & 764.79 \\
\hline 5. & Kuzhalmannam & 287.87 & 70.75 & 210.29 & 61.61 & 275.00 \\
\hline 6. & Malampuzha & 248.70 & 78.54 & 458.37 & 63.01 & 187.71 \\
\hline 7. & Mannarkkad & 247.12 & 81.49 & 453.91 & 81.78 & 85.26 \\
\hline 8. & Nenmara & 281.15 & 70.81 & 387.50 & 189.37 & 522.32 \\
\hline 9. & Ottappalam & 233.30 & 59.56 & 394.53 & 44.57 & 83.32 \\
\hline 10. & Palakkad & 248.44 & 63.43 & 379.67 & 70.56 & 184.16 \\
\hline 11. & Pattambi & 254.81 & 68.94 & 349.69 & 64.93 & 113.65 \\
\hline 12. & Sreekrishnapuram & 217.41 & 73.41 & 579.37 & 56.01 & 88.33 \\
\hline 13. & Thrithala & 285.42 & 77.18 & 261.33 & 63.57 & 109.28 \\
\hline
\end{tabular}

Source: Compiled and computed by the researcher from Agricultural Statistics 2015 -2019 


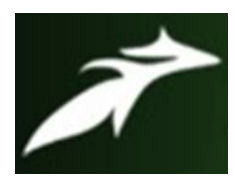

Lekshmi G.S et al, International Journal of Advances in Agricultural Science and Technology,

Vol.8 Issue.1, January-2021, pg. 119-124

ISSN: 2348-1358

Impact Factor: 6.057

NAAS Rating: 3.77

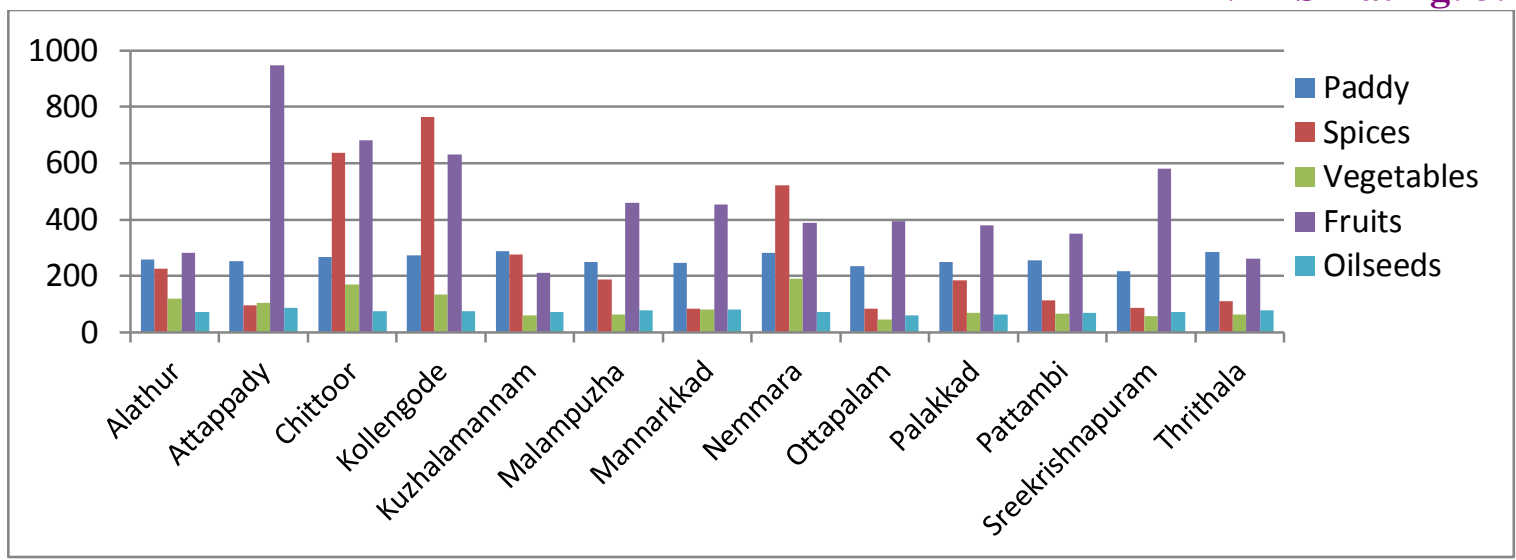

Figure 2: Productivity of crops $(\mathrm{Kg} / \mathrm{Ha})$

Rank scores of five main crops which was derived by applying Kendall's method is given in the table 2 .

Table 2: Ranking of Crops

\begin{tabular}{|l|l|l|l|l|l|l|l|l|}
\hline Sl.No. & Blocks & Rice & Coconut & Fruits & Vegetables & Spices & $\begin{array}{l}\text { Rank } \\
\text { Total }\end{array}$ & $\begin{array}{l}\text { Ranking } \\
\text { co-efficient }\end{array}$ \\
\hline 1. & Alathur & 6 & 8 & 11 & 4 & 5 & 34 & 6.8 \\
\hline 2. & Attappady & 8 & 1 & 1 & 5 & 10 & 25 & 5 \\
\hline 3. & Chittur & 5 & 6 & 2 & 2 & 2 & 17 & 3.4 \\
\hline 4. & Kollengode & 4 & 5 & 3 & 3 & 1 & 16 & 3.2 \\
\hline 5. & Kuzhalmannam & 1 & 10 & 13 & 11 & 4 & 39 & 7.8 \\
\hline 6. & Malampuzha & 9 & 3 & 5 & 10 & 6 & 33 & 6.6 \\
\hline 7. & Mannarkkad & 11 & 2 & 6 & 6 & 12 & 37 & 7.4 \\
\hline 8. & Nenmara & 3 & 9 & 8 & 1 & 3 & 24 & 4.8 \\
\hline 9. & Ottappalam & 12 & 13 & 7 & 13 & 13 & 58 & 11.6 \\
\hline 10. & Palakkad & 10 & 12 & 9 & 7 & 7 & 45 & 9 \\
\hline 11. & Pattambi & 7 & 11 & 10 & 8 & 8 & 44 & 8.8 \\
\hline 12. & Sreekrishnapuram & 13 & 7 & 4 & 12 & 11 & 47 & 9.4 \\
\hline 13. & Thrithala & 2 & 4 & 12 & 9 & 9 & 36 & 7.2 \\
\hline
\end{tabular}

Source: Compiled and computed by the researcher from Agricultural Statistics 2015 -2019

\subsection{Agricultural Efficiency}

Agricultural efficiency of Palakkad district was determined by selecting block as the unit of study by considering the five dominant crops. The blocks of Palakkad district were demarcated on the basis of their position in three categories which is given in the table 3 . 


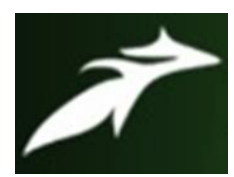

Lekshmi G.S et al, International Journal of Advances in Agricultural Science and Technology,

Vol.8 Issue.1, January-2021, pg. 119-124

ISSN: 2348-1358

Impact Factor: 6.057

NAAS Rating: 3.77

Table 3: Agricultural Efficiency of Palakkad District

\begin{tabular}{|l|l|l|}
\hline Categories & Productivity Index & Blocks \\
\hline High & $0-4$ & Chittur, Kollengode \\
\hline Medium & $4-8$ & $\begin{array}{l}\text { Alathur, Attappady, Kuzhalmannam, Malampuzha, } \\
\text { Mannarkkad, Nenmara, Thrithala }\end{array}$ \\
\hline Low & $8-12$ & Ottappalam, Palakkad, Pattambi, Sreekrishnapuram \\
\hline
\end{tabular}

Source: Compiled and computed by the researcher from Agricultural Statistics 2015 -2019

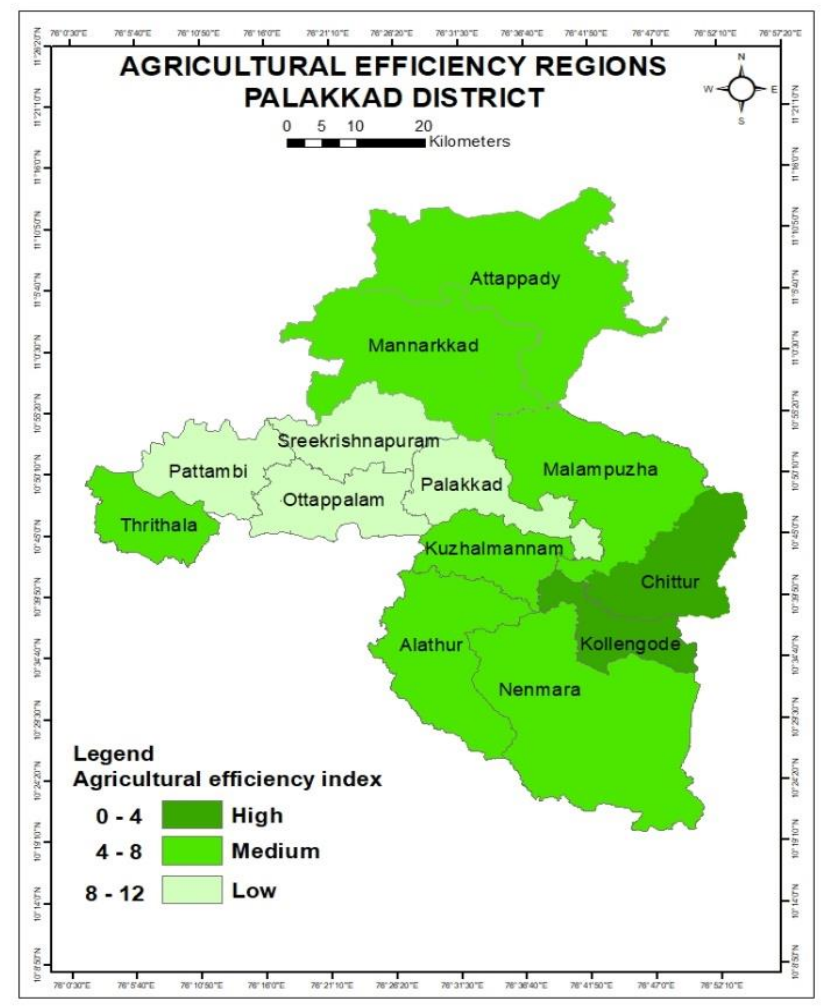

Figure 3: Agricultural Efficiency Regions

\subsubsection{High agricultural efficiency blocks}

Chittur and Kollengode blocks come under high agricultural efficiency regions. Presence of water bodies and irrigation facilities helps to increase agricultural efficiency in these regions. Technological development is also an important factor behind the high agricultural efficiency in these blocks.

\subsubsection{Medium agricultural efficiency blocks}

Alathur, Attappady, Kuzhalmannam, Malampuzha, Mannarkkad, Nenmara and Thrithala blocks are placed in the category of medium agricultural efficiency regions. The high population density and increased rate of sand mining activities has led to this situation in the above blocks. 


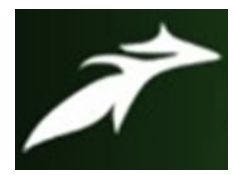

Lekshmi G.S et al, International Journal of Advances in Agricultural Science and Technology,

Vol.8 Issue.1, January-2021, pg. 119-124

ISSN: 2348-1358

Impact Factor: 6.057

NAAS Rating: 3.77

\subsubsection{Low agricultural efficiency blocks}

Under low agricultural efficiency, remaining four blocks namely Ottappalam, Palakkad, Pattambi and Sreekrishnapuram are included. Irrigation facilities are inadequate in these areas along with the increased population, increasing urbanisation and its allied activities led to low agricultural efficiency in these regions.

\section{Suggestions}

For achieving positive agricultural efficiency, many factors have to be dealt with importance. The adoption of new varieties of seeds and scientific use of organic manure is suggested. For better agricultural output, water quality testing and soil testing should be done. Construction and renovation of water bodies also helps to increase agricultural efficiency.Curbing sand mining activities is very important in the study area. So, addressing these factors can increase the efficiency of crop production which will help in improving the socioeconomic conditions of small and marginal farmers.

\section{Conclusion}

The assessment of agricultural efficiency reveals that except two blocks, rest of the blocks in Palakkad district has medium and low agricultural efficiency. The present situation reveals that, a meticulous planning is needed for increasing agricultural efficiency and implementing agricultural development efforts in a proper manner. The need of the hour is to increase the yield of individual crops per unit area to feed the fast growing population with the green revolution technology. Blocks with low agricultural efficiency need special attention on priority basis so that their level of efficiency could be raised. Interest of farmers and agricultural labourers should also be safeguarded.

\section{References}

[1]. Agricultural Statistics, 2015-2019, Department of Economics and Statistics, Government of Kerala, Palakkad.

[2]. Dutta S., 2012, Assessment of Agricultural Efficiency and Productivity: A Study of Hugli District, West Bengal, India, International Journal of Current Research, 4,11, pp. 190-195.

[3]. Mukherjee S.P., and Khan Z.T., 2016, Agricultural Efficiency and Productivity of Fringe of Raipur City, Chhattisgarh, International Journal of Innovative Research and Development, 5,1, pp.105-111.

[4]. Pandey A., and Dwivedi C.S., 2017, Disparities in Agricultural Productivity in Ambedkarnagar District, International Journal of Reviews and Research in Social Sciences, 5,3, pp.147-151.

[5]. Premakumar K., Anandan R., and Nagarathinam S.R., 2015, A study on crop combination regions in Palakkad district, Kerala, International Journal of Geomatics and Geosciences, 6, 2, pp. 1430- 1441. 